OPEN ACCESS

Edited by:

Zhi Sheng,

Virginia Tech, United States

Reviewed by:

Vijay Pandey,

National University of Singapore,

Singapore

Luca Tamagnone,

Institute for Cancer Research and Treatment (IRCC), Italy

*Correspondence:

Peige Du

dupeigedo@sina.com

Yu Sheng

shengyushirley@126.com

Specialty section:

This article was submitted to

Cancer Molecular Targets and Therapeutics,

a section of the journal

Frontiers in Pharmacology

Received: 15 November 2018

Accepted: 12 March 2019

Published: 28 March 2019

Citation:

Liu G, An L, Zhang H, Du P and

Sheng $Y$ (2019) Activation

of CXCL6/CXCR1/2 Axis Promotes

the Growth and Metastasis

of Osteosarcoma Cells in vitro

and in vivo. Front. Pharmacol. 10:307.

doi: 10.3389/fphar.2019.00307

\section{Activation of CXCL6/CXCR1/2 Axis Promotes the Growth and Metastasis of Osteosarcoma Cells in vitro and in vivo}

\author{
Guangchen Liu', Liping An², Hongmei Zhang ${ }^{3}$, Peige Du ${ }^{2 *}$ and Yu Sheng ${ }^{2 *}$ \\ ${ }^{1}$ Department of Traumatic Orthopedics, The First Hospital of Jilin University, Changchun, China, ${ }^{2}$ College of Pharmacy, \\ Beihua University, Jilin, China, ${ }^{3}$ Department of Pharmacy, The First Hospital of Jilin University, Changchun, China
}

Osteosarcoma (OS) is a malignant primary bone tumor with high metastatic rate. C-X-C motif chemokine ligand 6 (CXCL6) and its receptor C-X-C motif chemokine receptor $1 / 2$ (CXCR1/2) have been found to participate in the process of carcinogenesis. In this study, we evaluated the role of CXCL6/CXCR1/2 axis in proliferation and metastasis of OS cells. According to our results, the mRNA and protein expressions of CXCL6, CXCR1, and CXCR2 in multiple OS cell lines were determined. Treatment with exogenous CXCL6 for more than $72 \mathrm{~h}$ significantly promoted the proliferation of OS cells. Blocking the effect of endogenous CXCL6 restrained the migration, invasion and epithelial-mesenchymal transition (EMT) as evidenced by increased E-cadherin level, decreased N-cadherin and Snail levels in OS cells. On the contrary, exogenous CXCL6 administration enhanced the migration and invasive abilities of OS cells. Moreover, silencing of CXCR1/2 suppressed migration, invasion and EMT of OS cells with or without treatment with exogenous CXCL6. In addition, exogenous CXCL6 promoted the activation of PI3K/AKT and $\beta$-catenin signaling pathways, which could be repressed by CXCR2 knockdown. Inactivation of PI3K/AKT or $\beta$-catenin pathway by specific inhibitors effectively suppressed CXCL6-induced migration, invasion and EMT of OS cells. Finally, overexpression of CXCL6 significantly contributed to tumor growth, pulmonary metastasis and activation of PI3K/AKT and $\beta$-catenin pathways in nude mice in vivo, which were repressed by treatment with CXCR2 antagonist. Our results suggest that CXCL6/CXCR1/2 axis promotes the proliferation and metastasis of OS cells.

Keywords: osteosarcoma, CXCL6/CXCR1/2 axis, metastasis, PI3K/AKT, $\beta$-catenin

\section{INTRODUCTION}

Osteosarcoma (OS) is one of common malignant primary bone tumors, which frequently occurs in adolescents or children and accounts for about $2.4 \%$ of all tumors in children (Ottaviani and Jaffe, 2009). At present, surgery combination with chemotherapy is a widely used treatment for OS. A great deal of patients with OS may suffer distant metastasis, and the prognosis is poor (Tan et al., 2009). Until the mid-1980s, the 5-year survival of OS had been increased from 20 to $70 \%$ 
(Chou and Gorlick, 2006). However, over the past decades, the 5-year survival of OS has not been further improved. Therefore, searching novel effective therapeutic targets for OS is of great significance.

Cytokines of the C-X-C motif chemokine ligand (CXCL) family serve different functions depending on the presence or absence of the amino acid triplet ELR in their protein sequence. In these regards, ELR+CXCL presents proangiogenic properties, whereas ELR-CXCL has antiangiogenic properties (Grepin et al., 2014). CXCL6, also known as Granulocyte Chemotactic Protein 2 (GCP2), was firstly found in MG-63, one of OS cell lines, by Proost et al. (1993). CXCL6 is one of ELR+CXCLs. Similar to CXCL8, also an ELR+CXCL, CXCL6 regulates its downstream pathways via binding with $\mathrm{C}-\mathrm{X}-\mathrm{C}$ motif chemokine receptor 1 (CXCR1) and C-X-C motif chemokine receptor 2 (CXCR2; Wolf et al., 1998). Previous research has confirmed the role of CXCL8/CXCR axis in the occurrence and development of OS (Du et al., 2018). It is noteworthy that the CXCL6 level in serum of OS patients has been found to be up-regulated and recombinant CXCL6 could promote the proliferation of OS cells ( $\mathrm{Li}$ et al., 2011). It is widely acknowledged that CXCL6 promotes the growth and metastasis of various cancers, including non-small cell lung cancer (Li et al., 2018), colon cancer (Ma et al., 2017), and melanoma (Verbeke et al., 2011). The angiogenesis-promoting effect of CXCL6 on tumorigenesis and metastasis has also been confirmed (Ma et al., 2017). However, the role of CXCL6/CXCR1/2 axis in OS has not been determined. Based on the above research background, we speculate that CXCL6/CXCR axis may play important roles in the progression of OS.

It has been reported that about $30-40 \%$ of OS patients may undergo metastasis, and their 5-year survival rates were reduced to only about 20\% (Wu et al., 2009). So, investigating the mechanisms of invasion and metastasis of OS cells is quite necessary. Epithelial mesenchymal transition (EMT) is a biological process that epithelial cells transform into mesenchymal cells, which promotes the migration, invasion and distant metastasis of cancer cells. Growing evidence has demonstrated that inhibition of EMT effectively suppressed the migration and invasion of OS cells (Jin et al., 2017; Zhang et al., 2017). It has been well documented that CXCR2 is closely related with EMT in various tumors (Sobolik et al., 2014; Zhou et al., 2015; Xiang et al., 2017). However, the role of CXCL6/CXCR1/2 axis in migration, invasion, and EMT of OS cells is not clear, which needs to be clarified.

In this study, we performed in vitro and in vivo experiments to investigate the role of CXCL6/CXCR1/2 axis in the growth and metastasis of OS and its related mechanisms.

\section{MATERIALS AND METHODS}

\section{Reagents}

Recombinant human CXCL6 (rhCXCL6) was purchased from PeproTech (Rocky Hill, NJ, United States). AntiCXCL6 antibody was obtained from Abcam (Cambridge, United Kingdom). LY294002 was purchased from Beyotime
Biotechnology (Haimen, China). XAV939 was purchased from MedChemExpress (Monmouth Junction, NJ, United States).

\section{Cell Lines and Culture}

MG63, 143B, SaOS-2, and U2OS cell lines were obtained from Zhong Qiao Xin Zhou Biotechnology Co., Ltd., (Shanghai, China). MG63, SaOS-2, and U2OS cells were cultured in Dulbecco's Modified Eagle Medium (DMEM, $\mathrm{BD}$, United States) supplemented with $10 \%$ fetal bovine serum (FBS, Hyclone, Logan, UT, United States). 143B cells were cultured in Eagle's minimum essential medium (EMEM, Zhong Qiao Xin Zhou Biotechnology, Shanghai, China) supplemented with 10\% FBS (Hyclone, Logan, UT, United States). All the cells were maintained at $37^{\circ} \mathrm{C}$, under a $5.0 \% \mathrm{CO}_{2}$ atmosphere.

\section{Transient Transfection and Lentivirus Infection}

The siRNAs were synthesized by Genepharma Inc., (Shanghai, China). The sequences of CXCR2 and negative control (NC) siRNAs were as follows: si-CXCR2-1 (sense: $5^{\prime}$ CCGUCUACUCAUCCAAUGUUA-3'; anti-sense: 5'-UAACAU UGGAUGAGUAGACGG-3'), si-CXCR2-2 (sense: 5'-GGCAAC AAUACAGCAAACUTT-3'; anti-sense: 5'-AGUUUGCUGUAU UGUUGCCTT-3'), NC (sense: 5'-UUCUCCGAACGUGUC ACGUTT-3'; anti-sense: 5'-ACGUGACACGUUCGGAGA ATT- $\left.3^{\prime}\right)$. The OS cells were transiently transfected with the abovesiRNAs by Lipofectamine 2000 (Invitrogen, CA, United States) according to the instructions. The full length CXCL6 was synthesized and cloned into lentiviral vector. Then the $293 \mathrm{~T}$ cells were transfected with lentiviral vector to produce lentivirus particles (Wanleibio, Shenyang, China). The U2OS cells were infected with CXCL6 or vector lentivirus particles and selected with puromycin (Solarbio, Beijing, China) to generate cells that stably express CXCL6.

\section{Cell Growth Assay}

The growth of OS cells was assessed by cell counting kit- 8 (CCK8). OS cells were seeded into 96 -well plates $\left(3 \times 10^{3}\right.$ cells/well). After treatment with $100 \mathrm{ng} / \mathrm{ml} \mathrm{rhCXCL6}$ for 0,12 , $24,48,72$, and $96 \mathrm{~h}$, cells were incubated with $10 \mu \mathrm{l}$ of CCK8 (Beyotime, Haimen, China) at $37^{\circ} \mathrm{C}$ for $1 \mathrm{~h}$. The absorbance values at $450 \mathrm{~nm}$ were detected by a microplate reader (BioTek, Winooski, VT, United States).

\section{Enzyme Linked Immunosorbent Assay (ELISA)}

The CXCL6 level in the supernatant fluid of cultured OS cells was determined by a CXCL6 ELISA kit (BOSTER, Wuhan, China) according to the manufacturer's protocol. The concentration of CXCL6 was calculated according to the standard curve.

\section{Transwell Migration and Invasion Assays}

The invasion and migration of OS cells were determined by Transwell chamber (Corning, NY, United States) coated with or without Matrigel (BD Biosciences, Franklin Lakes, 
NJ, United States), respectively. Briefly, the OS cells in $200 \mu \mathrm{l}$ serum-free medium were added into the upper chambers, while $800 \mu \mathrm{l}$ medium containing 30\% FBS was added into the lower chambers. After receiving different treatments for $24 \mathrm{~h}$, the non-invasive cells on the upper surface were erased. The cells on the lower surface were fixed in $4 \%$ paraformaldehyde, and stained with $0.4 \%$ crystal violet. Under a microscope (Olympus, Tokyo, Japan), the number of invasive or migrated cells was counted in five random fields and the images were taken at a magnification of $200 \times$.

\section{Immunofluorescence Staining}

The OS cells with different treatments were cultured in slides, fixed in $4 \%$ paraformaldehyde for $15 \mathrm{~min}$, incubated with $0.1 \%$ Triton X-100 for $30 \mathrm{~min}$, and blocked with 10\% goat serum for $15 \mathrm{~min}$. Then the slides were incubated with primary antibodies against E-cadherin (1:50, Proteintech, Rosemont, IL, United States), $\mathrm{N}$-cadherin (1:50, Proteintech) at $4^{\circ} \mathrm{C}$ overnight. FITC-labeled anti-mouse IgG (1:200, Beyotime, Haimen, China) was added for $1 \mathrm{~h}$ at room temperature. Then the nuclei were counterstained with DAPI. The slides were observed under a fluorescence microscope (Olympus, Tokyo, Japan) at a magnification of $400 \times$.

\section{Western Blot Assay}

The OS cells or tumor tissues were homogenized and lysed by RIPA Lysis Buffer (Beyotime), supplemented with $1 \%$ PMSF (Beyotime). Nuclear and Cytoplasmic Protein Extraction Kit (Beyotime) was used to extract nuclear protein. Protein concentration was measured by Enhanced BCA Protein Assay Kit (Beyotime). The protein samples were separated on SDA-PAGE and transferred to PVDF membranes (Millipore, Massachusetts, United States). After being blocked with 5\% skimmed milk for $1 \mathrm{~h}$, the membranes were incubated with primary antibodies CXCR1 (1:400, BOSTER, Wuhan, China), CXCR2 (1:400, BOSTER), CXCL6 (1:1000, Abcam, Cambridge, United Kingdom), E-cadherin (1:2000, Proteintech, Rosemont, IL, United States), N-cadherin (1:1000, Proteintech), Snail (1:500, Proteintech), p-AKT (1:1000, Cell Signaling Technology, Trask Lane Danvers, MA, United States), AKT (1:1000, Cell Signaling Technology), $\beta$-catenin (1:1000, Cell Signaling Technology), MMP9 (1:500, Sangon Biotech, Shanghai, China), Histone H3 (1:1000, Abcam), and $\beta$-actin (1:500, Santacruz Biotechnology, Santa Cruz, CA, United States) at $4^{\circ} \mathrm{C}$ overnight. Then the membranes were incubated with HRP-labeled Goat Anti-Rabbit or Goat Anti-Mouse secondary antibodies (1:5000, Beyotime) for $45 \mathrm{~min}$ at $37^{\circ} \mathrm{C}$ and developed using the BeyoECL Plus (Beyotime). Protein bands were analyzed using Gel-Pro-Analyzer software (Media Cybernetics, Rockville, MD, United States).

\section{Real-Time PCR}

Total RNA was isolated from OS cells using TRIpure total RNA isolation kit (BioTeke, Beijing, China) and reverse transcribed into cDNA by Super M-MLV reverse transcriptase (BioTeke). Real-Time PCR was carried out using $2 \times$ Power Taq
PCR MasterMix (BioTeke). The primers were synthesized by Sangon Biotech (Shanghai, China) and listed in Table 1. The mRNA expression was normalized to $\beta$-actin and calculated by $2^{-\Delta \Delta C T}$ method.

\section{Gelatin Zymography}

After different treatments, the culture medium of OS cells was collected. Then samples $(60 \mu \mathrm{g})$ were subjected to $10 \%$ polyacrylamide gel containing gelatin. The gel was washed two times in washing buffer $(2.5 \%$ Triton $\mathrm{X}-100,50 \mathrm{mM}$ Tris- $\mathrm{HCl}, 5 \mathrm{mM} \mathrm{CaCl}_{2}, 1 \mu \mathrm{M} \mathrm{ZnCl}, \mathrm{pH}$ 7.6) for $40 \mathrm{~min}$, and incubated in $50 \mathrm{mM}$ Tris- $\mathrm{HCl}, 5 \mathrm{mM} \mathrm{CaCl}_{2}, 1 \mu \mathrm{M}$ $\mathrm{ZnCl}_{2}, 0.02 \%$ Brij, $0.2 \mathrm{M} \mathrm{NaCl}$ at $37^{\circ} \mathrm{C}$ for $40 \mathrm{~h}$. Then the gel was stained in $0.05 \%$ Coomassie Blue G-250 for $3 \mathrm{~h}$ and destained in 30\% methanol and 10\% acetic acid for $0.5 \mathrm{~h}, 20 \%$ methanol and $10 \%$ acetic acid for $1 \mathrm{~h}, 10 \%$ methanol and $5 \%$ acetic acid for $2 \mathrm{~h}$. The clear bands were imaged and analyzed.

\section{In vivo Tumor Xenograft}

U2OS cells $\left(1 \times 10^{7}\right)$ that infected with lentivirus (LV-NC or LV-CXCL6) were subcutaneously injected into the nude mice (Beijing HFK Bioscience Co., Ltd., China). There were three experimental groups ( $n=6$ per group): LV-NC, LV-CXCL6, LVCXCL6+SB225002. The mice in LV-CXCL6+SB225002 group were intraperitoneally injected with $200 \mu \mathrm{g}$ SB225002 in DMSO three times a week. The mice in the other groups were injected with DMSO in the same volume. Tumor diameter and width were measured every 3 days after the formation of xenografted tumor. Twenty-three days after the inoculation of U2OS cells, the mice were sacrificed by euthanasia. The tumor tissues were collected and weighed. This study was carried out in accordance with the recommendations of international ethical guidelines and the National Institutes of Health Guide concerning the Care and Use of Laboratory Animals. The protocol was approved by the Institutional Animal Care and Use Committee of Beihua University Laboratory Animal Ethics Committee (approval number of the ethical certificate: 2017060207).

\section{In vivo Metastasis Assay}

To evaluate pulmonary metastasis, $1 \times 10^{6} \mathrm{U} 2 \mathrm{OS}$ cells were intravenously injected into nude mice via the tail vein. The grouping and treatment were performed as described above. Four

TABLE 1 | Oligonucleotide primer sets for real-time PCR.

\begin{tabular}{llc}
\hline Name & Sequence $\left(\mathbf{5}^{\prime} \mathbf{- \mathbf { 3 } ^ { \prime } )}\right.$ & Length \\
\hline CXCL6 F & ACTTGTTACGCGTTACGCTGAG & 23 \\
CXCL6 R & TCTTCAGGGAGGCTACCACTT & 22 \\
CXCR1 F & CCCTGCCCTTCTCCTTTC & 20 \\
CXCR1 R & ACACCATCCGCCATTTGCT & 20 \\
CXCR2 F & TTCCGAAGGACCGTCTACTCA & 21 \\
CXCR2 R & AGGGTGAATCCGTAGCAGAAC & 21 \\
$\beta$-actin F & CTTAGTTGCGTTACACCCTTCTTG & 25 \\
$\beta$-actin R & CTGTCACCTTCACCGTTCCAGTT & 24
\end{tabular}


weeks after the inoculation of U2OS cells, the mice were sacrificed and the lung metastatic nodules were observed.

\section{Immunohistochemical Staining}

The tumor tissues were fixed in formaldehyde, embedded in paraffin and cut into $5-\mu \mathrm{m}$ sections. Then the sections were deparaffinized and rehydrated in gradient ethanol solutions. After receiving heat-induced epitope retrieval, the sections were blocked in goat serum for $15 \mathrm{~min}$ at room temperature. Then the sections were incubated with PCNA (1:50, Santa Cruz, CA, United States) as the primary antibody at $4^{\circ} \mathrm{C}$ overnight. Biotin-labeled Goat Anti-Mouse IgG (1:200, Beyotime) was used. Then the sections were labeled with horseradish peroxidase, and visualized by $3,3^{\prime}$-Diaminobenzidine (DAB, Solarbio). The images were taken under a microscope at a magnification of $400 \times$.

\section{Statistical Analysis}

Data are expressed as mean \pm SD. GraphPad Prism 5 software (La Jolla, CA, United States) was used to perform statistical analysis. Student's $t$-test was used for comparison between two groups. One-way analysis of variance (ANOVA) followed by Bonferroni's Multiple Comparison Test was performed when comparing several groups. $P<0.05$ is considered to be statistically significant.

\section{RESULTS}

\section{Expressions of CXCL6, CXCR1, and CXCR2 in OS Cells}

As shown in Figures 1A-C, the mRNA expressions of CXCL6, CXCR1 and CXCR2 in various OS cells (MG63, 143B, SaOS2, U2OS) were determined. Among these OS cells, the mRNA expressions of CXCL6, CXCR1 and CXCR2 were highest in MG63. Similarly, the protein levels of CXCL6, CXCR1 and CXCR2, as detected by western blot, were highest in MG63 (Figures 1D-I).

\section{Effect of rhCXCL6 on the Proliferation of OS Cells}

To assess the effect of rhCXCL6 on the proliferation of OS cells, CCK8 assay was performed. As illustrated in Supplementary Figures S1A-D, the proliferation of MG63, 143B, SaOS-2, and U2OS cells was significantly promoted after treatment with rhCXCL6 for more than $72 \mathrm{~h}$. There was no significant difference within $48 \mathrm{~h}$ of rhCXCL6 treatment.

\section{Effect of Anti-CXCL6 Antibody on the Migration, Invasion and EMT of OS Cells}

The secretion level of CXCL6 by OS cells was detected by ELISA. As presented in Figure 2A, the level of CXCL6 secreted

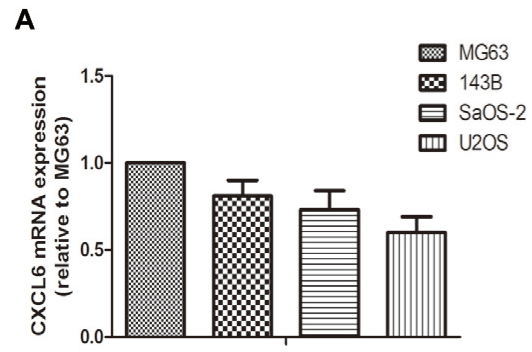

D

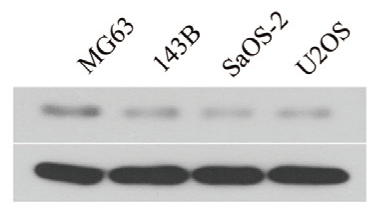

CXCL6 $\beta$-actin

G

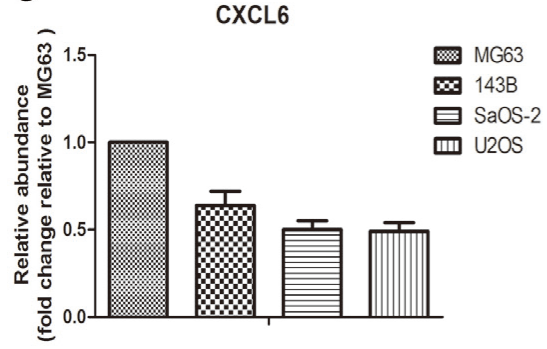

B

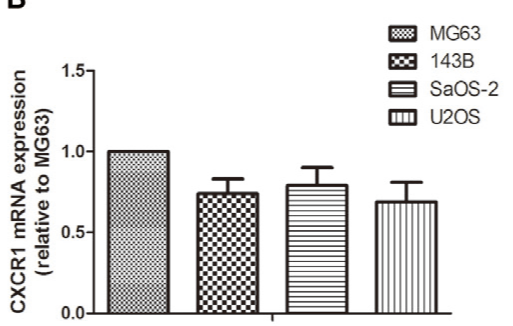

E

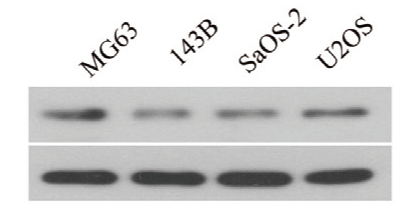

H

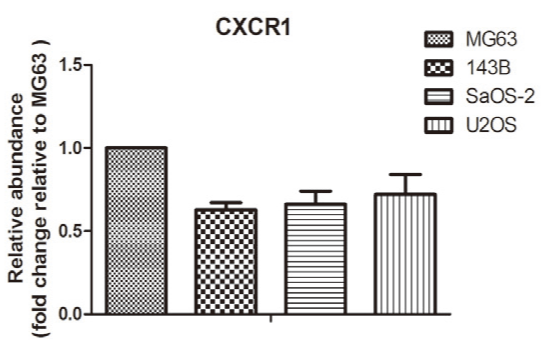

C

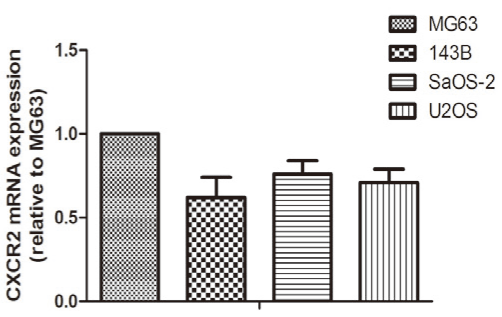

$\mathbf{F}$

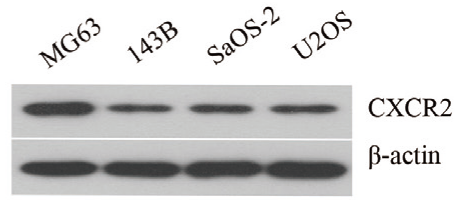

I

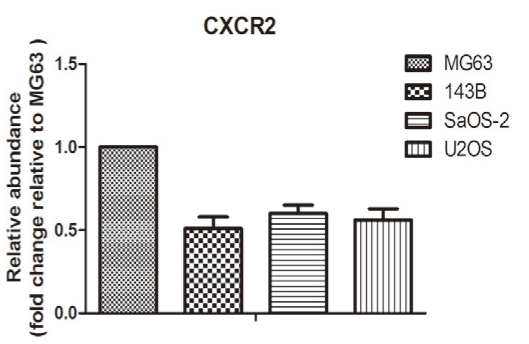

FIGURE 1 | Expressions of CXCL6, CXCR1, and CXCR2 in osteosarcoma (OS) cells. The mRNA expressions of CXCL6 (A), CXCR1 (B), and CXCR2 (C) in multiple OS cell lines were evaluated by real-time PCR. The protein levels of CXCL6 (D), CXCR1 (E), and CXCR2 (F) in multiple OS cell lines were detected by western blot assay. (G-I) The protein quantification histograms were shown. 
A

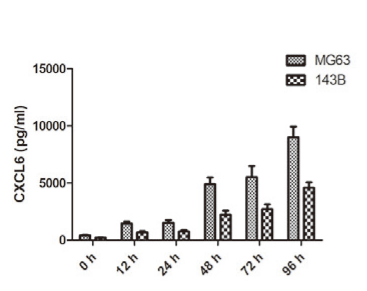

E

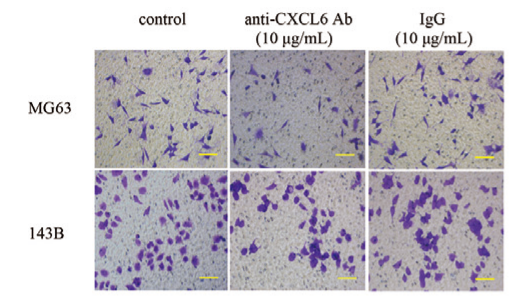

H control anti-CXCL6 Ab control

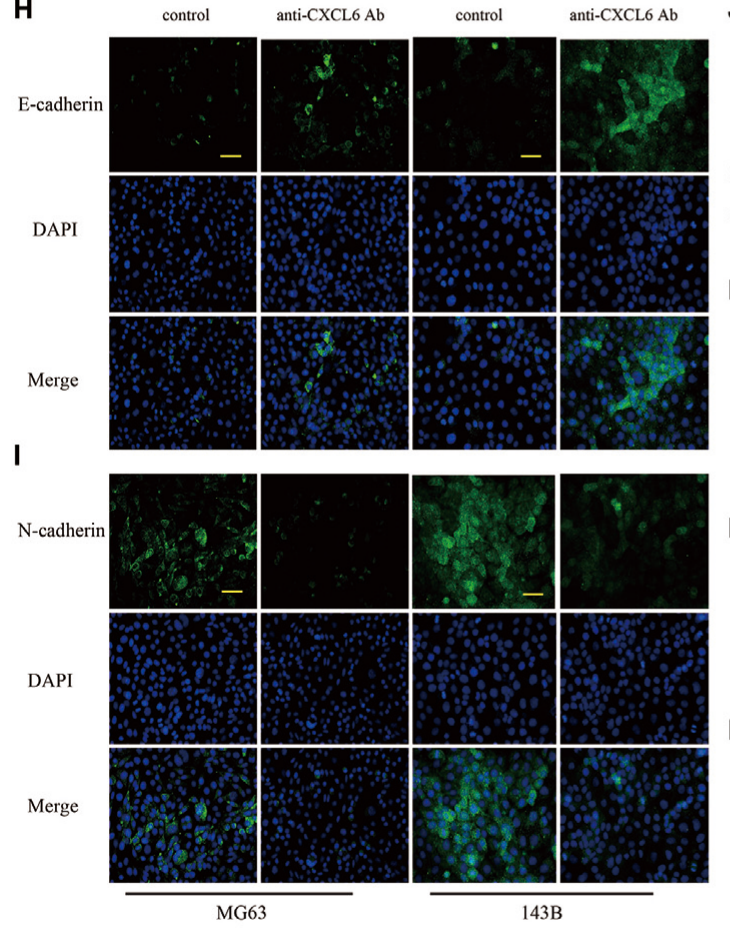

Q

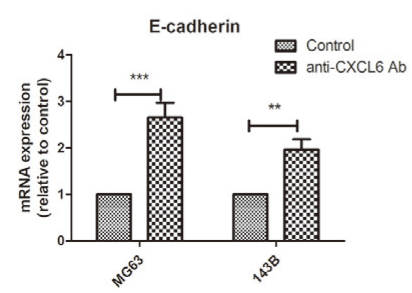

B

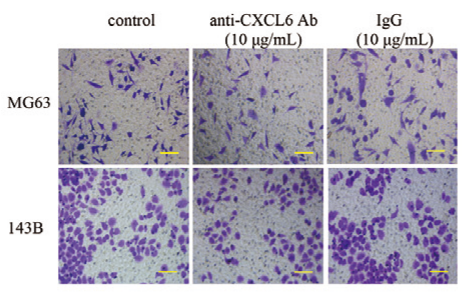

F

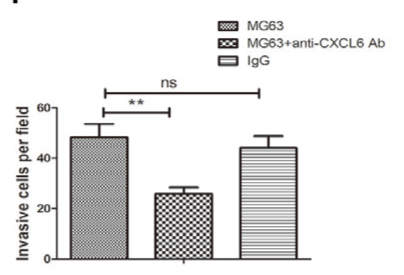

D

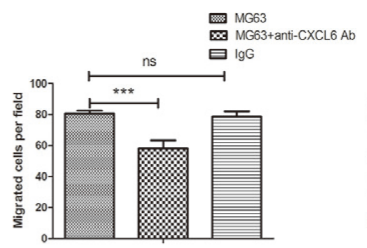

G
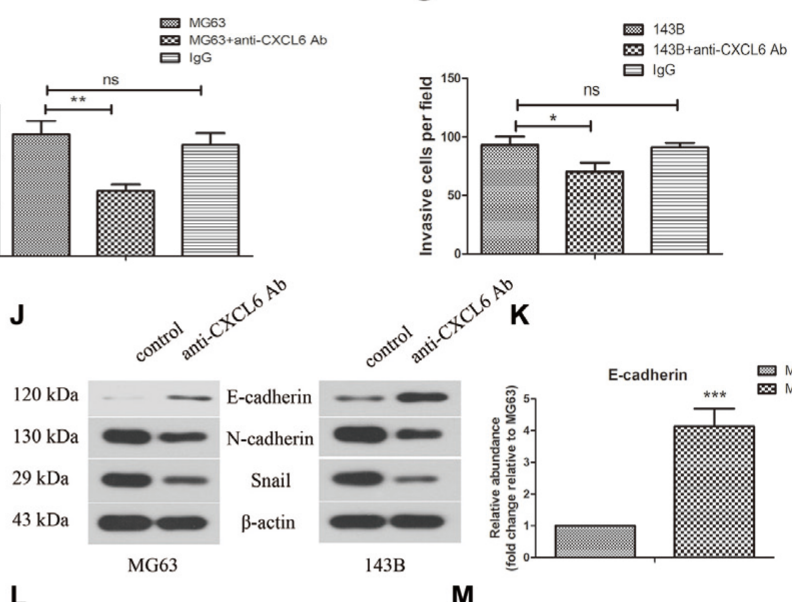

K
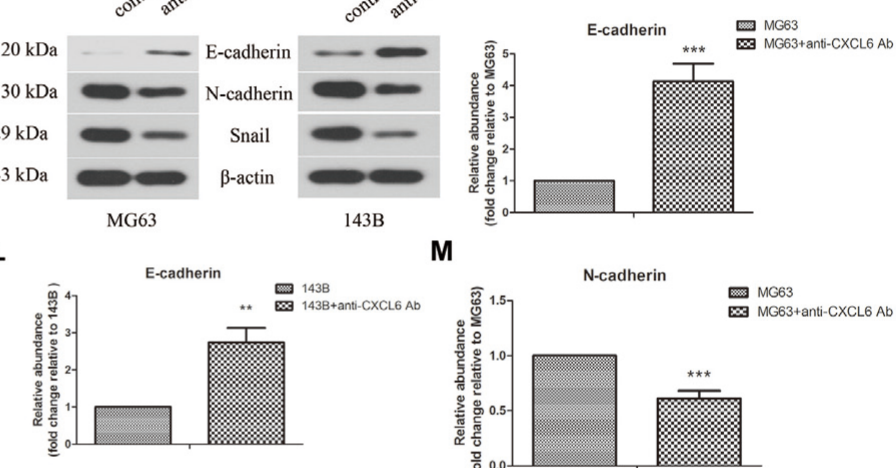

N
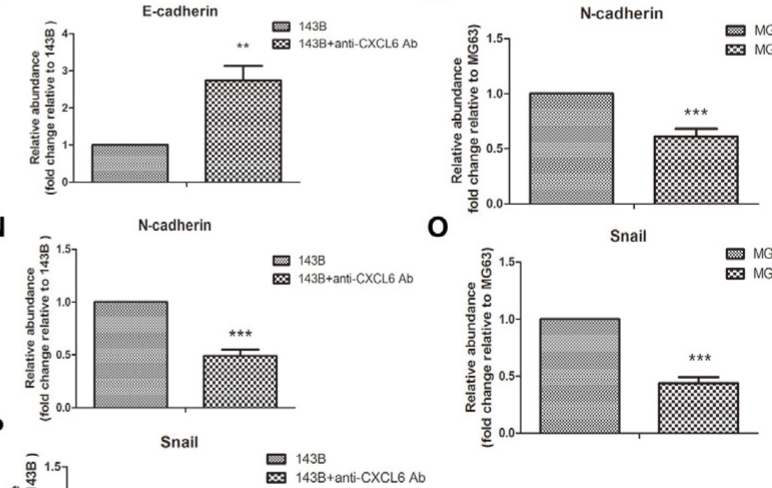

0
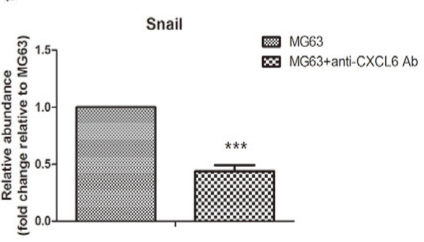

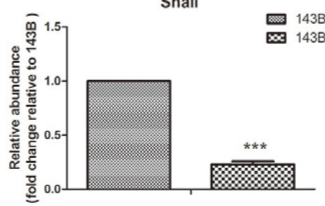

R

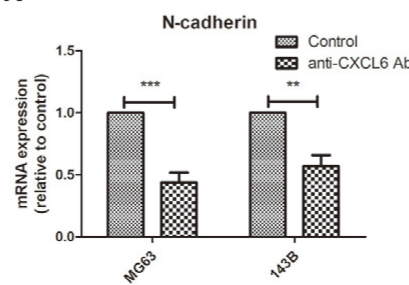

S

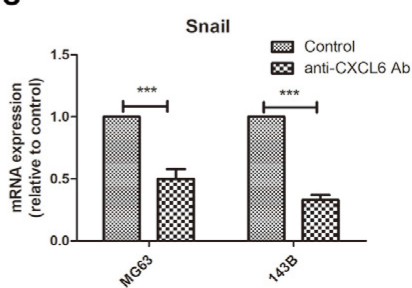

FIGURE 2 | Anti-CXCL6 antibody inhibited the migration, invasion and EMT of OS cells. OS cells were cultured for $72 \mathrm{~h}$, then incubated with anti-CXCL6 antibody $(10 \mu \mathrm{g} / \mathrm{mL}$ ) or a control antibody (lgG, $10 \mu \mathrm{g} / \mathrm{mL}$ ) for another $24 \mathrm{~h}$. (A) The level of CXCL6 in the supernatant fluid of cultured MG63 and 143B cells was detected by ELISA. (B) The migration of MG63 and 143B cells was evaluated by Transwell assay (no matrigel). Scal bar = $100 \mu \mathrm{m}$. (C,D) The number of migrated cells was shown. (E) The invasion of MG63 and 143B cells was assessed by Transwell assay (matrigel). Scal bar = $100 \mu \mathrm{m}$. (F,G) The number of invasive cells was shown. The expressions of E-cadherin (H) and N-cadherin (I) in MG63 and 143B cells were determined by immunofluorescence assay. Scal bar $=50$ $\mu \mathrm{m}$. ( $\mathbf{~})$ The protein levels of E-cadherin, N-cadherin, and Snail were evaluated by western blot assay. (K-P) The protein quantification histograms were shown. (Q-S) The mRNA expression of E-cadherin, N-cadherin, and Snail was detected by real-time PCR. ${ }^{*} P<0.05,{ }^{* *} P<0.01$, ${ }^{* * *} P<0.001$, versus the OS cell group. 
A

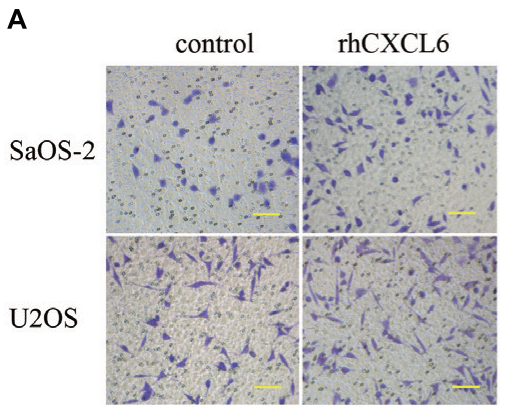

D

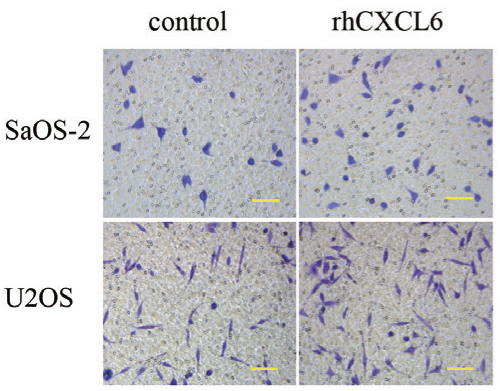

B

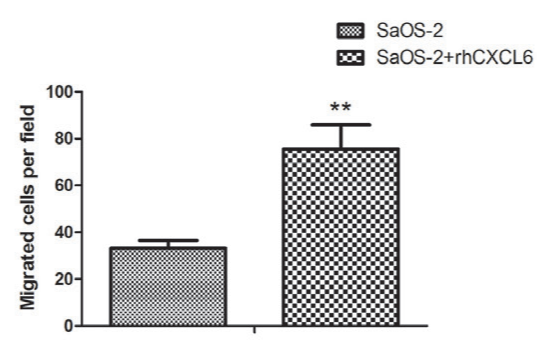

E

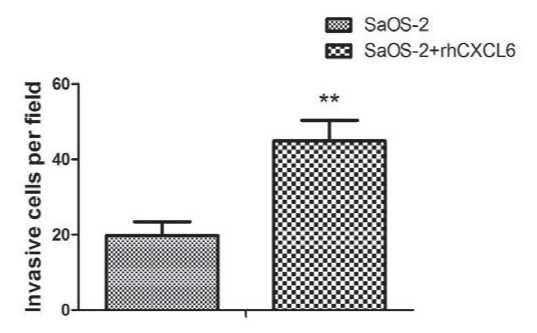

C

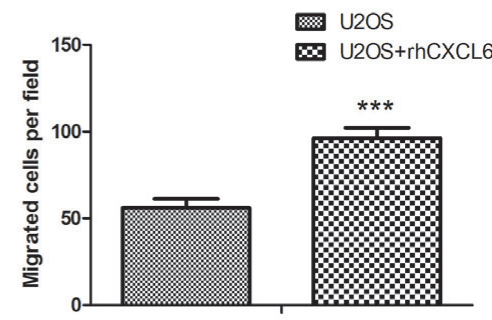

$\mathbf{F}$

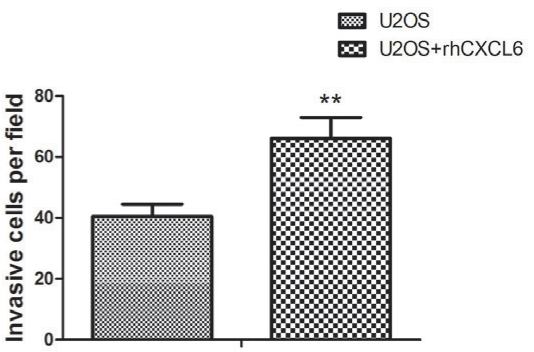

FIGURE 3 | Recombinant human (rh) CXCL6 facilitated the migration and invasion of OS cells. OS cells were treated with $100 \mathrm{ng} / \mathrm{ml}$ rhCXCL6 for 24 h. (A) The migration of SaOS-2 and U2OS cells was detected by Transwell assay (no matrigel). Scal bar $=100 \mu \mathrm{m}$. (B,C) The number of migrated cells was shown. (D) The invasion of SaOS-2 and U2OS cells was determined by Transwell assay (matrigel). Scal bar $=100 \mu \mathrm{m}$. (E,F) The number of invasive cells was shown. ${ }^{* *} P<0.01$, $* * * P<0.001$, versus the OS cell group.

from MG63 and 143B cells was up-regulated gradually with time prolonging and the increase in the number of cells. To block the function of secreted CXCL6, $10 \mu \mathrm{g} / \mathrm{ml}$ antiCXCL6 antibody was added to MG63 and 143B cells. To demonstrate the specificity of anti-CXCL6 antibody, the same amount of a control antibody (IgG) was used. As shown in Figures 2B-D, after treatment with anti-CXCL6 antibody for $24 \mathrm{~h}$, the migration ability of MG63 and 143B cells was restrained. Moreover, the invasive ability of MG63 and 143B cells was also inhibited by incubation with anti-CXCL6 antibody for $24 \mathrm{~h}$ (Figures 2E-G). However, incubation with IgG did not affect the migration and invasion of MG63 and 143B cells. As shown in Figures $\mathbf{2 H}, \mathbf{I}$, the immunofluorescence staining of E-cadherin was enhanced, while $\mathrm{N}$-cadherin was weakened in MG63 and 143B cells that received anti-CXCL6 antibody treatment. In addition, anti-CXCL6 antibody treatment resulted in increased protein level of E-cadherin, and decreased levels of N-cadherin and Snail in MG63 and 143B cells (Figures 2J-P). The mRNA expression of E-cadherin was increased, while $\mathrm{N}$-cadherin and Snail were decreased after incubation with antiCXCL6 antibody (Figures 2Q-S). These results indicated that blocking of endogenous CXCL6 function significantly restrained migration, invasion and EMT of MG63 and 143B cells.

\section{Effect of rhCXCL6 on the Migration and Invasion of OS Cells}

Furthermore, we investigated the role of exogenous CXCL6 in the migration and invasion of OS cells. Since blocking the function of endogenous CXCL6 could inhibit the migration and invasion of OS cells, as expected, the migration ability of SaOS-2 and U2OS cells was strikingly improved by treatment with rhCXCL6 for $24 \mathrm{~h}$ (Figures 3A-C). Consistently, rhCXCL6 treatment significantly promoted the invasion of SaOS-2 and U2OS cells (Figures 3D-F).

\section{CXCL6/CXCR1/2 Axis Contributed to Migration, Invasion, and EMT of OS Cells}

CXCR1 and CXCR2 are recognized as receptors of CXCL6, so we further evaluated the role of CXCL6/CXCR1/2 axis in migration, invasion, and EMT of OS cells. To achieve this, the expression of CXCR1/2 was inhibited by transfection with CXCR1/2 siRNAs. As shown in Figures 4A-D and Supplementary Figures S2A-D, the mRNA and protein expressions of CXCR1/2 in SaOS2 and U2OS cells were effectively repressed by transfection with CXCR1/2 siRNAs. Moreover, rhCXCL6-induced migration of SaOS-2 and U2OS cells was significantly inhibited by silencing of CXCR $1 / 2$ (Figures $4 \mathrm{E}-\mathrm{G}$ and Supplementary Figures S3A-C). Likewise, the invasive ability that enhanced by rhCXCL6 treatment was effectively suppressed by CXCR1/2 siRNAs in SaOS-2 and U2OS cells (Figures $4 \mathbf{H}-\mathbf{J}$ and Supplementary Figures S3D-F). In addition, rhCXCL6-induced increase in protein levels of MMP9 and Snail was evidently repressed by silencing of CXCR2 (Figures 4K-O). As detected by gelatin zymography and shown in Figures $4 \mathbf{P}-\mathbf{R}$, the activity of MMP9 in the supernatant fluid of cultured SaOS-2 and U2OS cells was distinctly increased by treatment with rhCXCL6, 


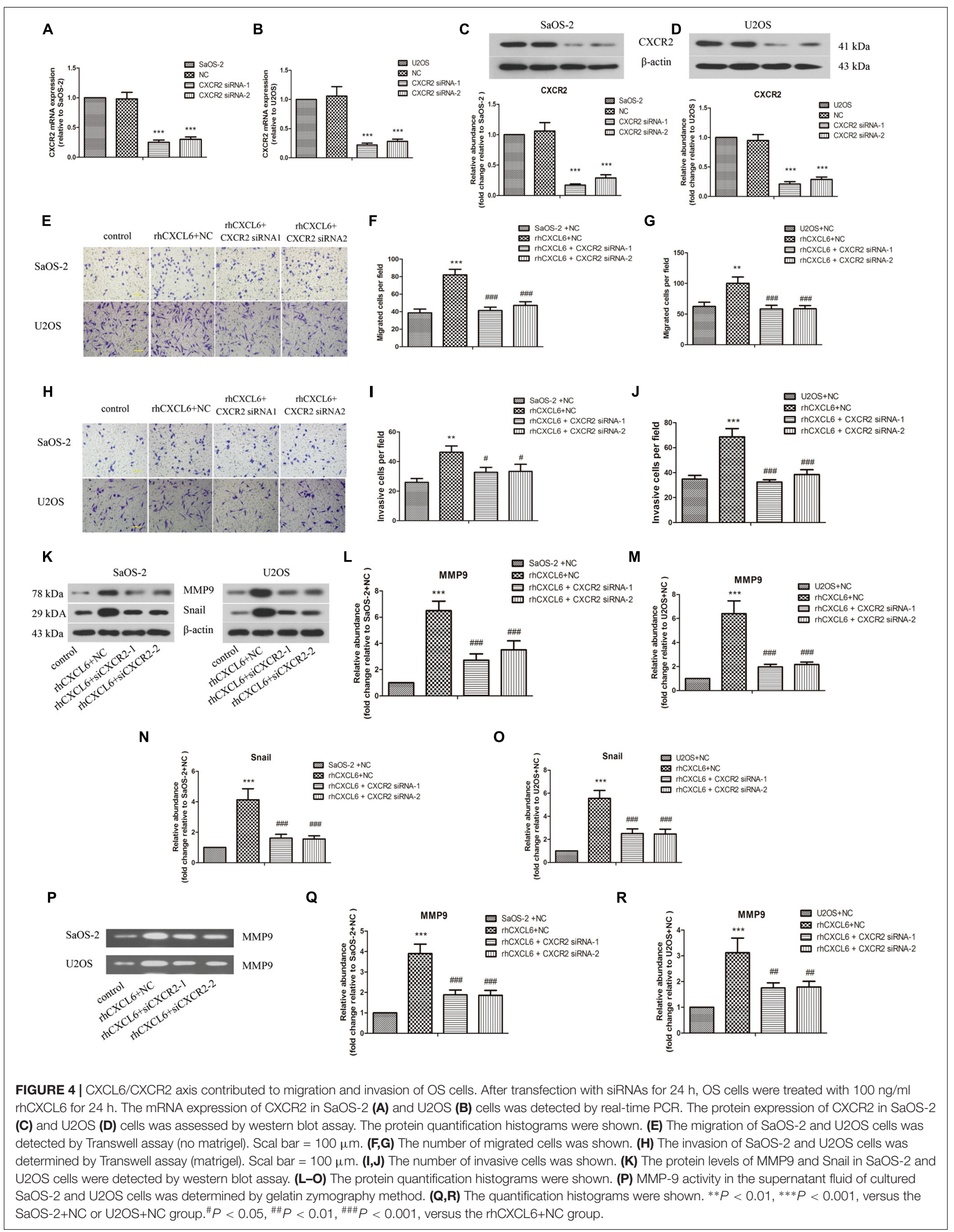




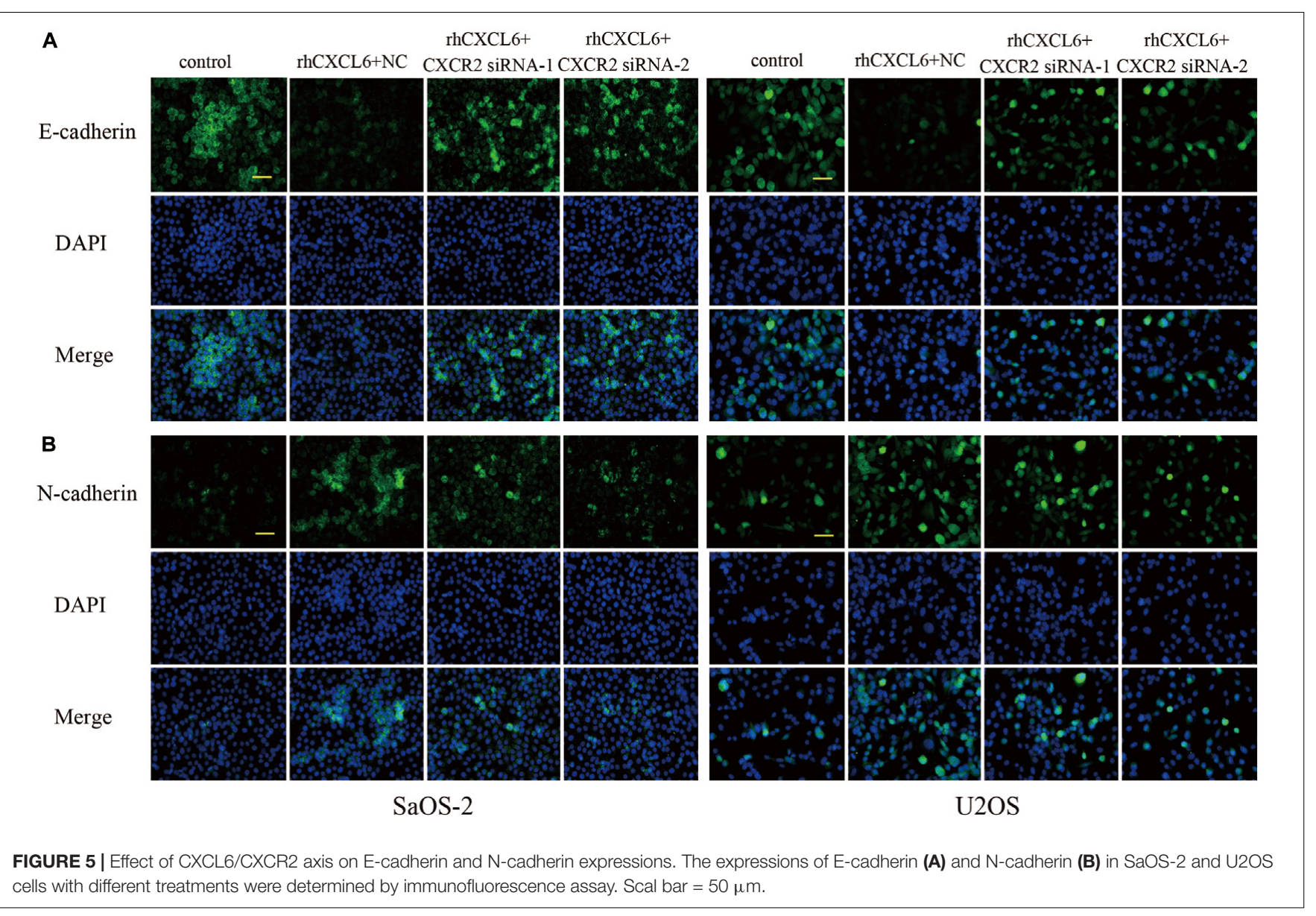

which could be restrained by silencing of CXCR2. As presented in Figures 5A,B silencing of CXCR2 significantly reversed rhCXCL6-induced decrease in E-cadherin expression, while increase in $\mathrm{N}$-cadherin expression in SaOS-2 and U2OS cells. The above results suggested that CXCL6/CXCR1/2 axis was involved in the regulation of migration, invasion, and EMT of OS cells.

\section{Inhibition of CXCR1/2 Repressed the Migration and Invasion of OS Cells}

As shown in Supplementary Figures S2E-J, inhibition of CXCR1/2 expression in SaOS-2 and U2OS cells by CXCR1/2 siRNAs repressed the migration and invasion of these cells accordingly.

\section{PI3K/AKT and $\beta$-Catenin Signaling Pathways Participated in the Regulation of Migration, Invasion and EMT by CXCL6/CXCR2 Axis in OS Cells}

To further evaluate the detailed mechanisms through which CXCL6/CXCR2 axis regulated malignant phenotype of OS cells, we focused on PI3K/AKT and $\beta$-catenin signaling pathways. As illustrated in Figures 6A-E, the ratio of p-AKT/AKT and nuclear $\beta$-catenin level was up-regulated by treatment with rhCXCL6, whereas knockdown of CXCR2 obviously inhibited the increased
p-AKT/AKT ratio and nuclear $\beta$-catenin level. Furthermore, incubation with LY294002 (AKTpathway inhibitor) or XAV939 ( $\beta$-catenin pathway inhibitor) strikingly suppressed rhCXCL6induced increase in migration and invasion ability of SaOS2 and U2OS cells (Figures 6F-K). Moreover, the decreased level of E-cadherin, increased levels of N-cadherin, Snail, and MMP9 induced by rhCXCL6 were evidently inhibited by administration of LY294002 or XAV939 (Figures 6L-T). As presented in Figures 6U-W, treatment with LY294002 or XAV939 significantly restrained the increased MMP9 activity induced by rhCXCL6.

\section{Effect of CXCL6/CXCR2 Axis on OS Tumor Growth and Pulmonary Metastasis in vivo}

As shown in Figures 7A,B lentivirus-mediated overexpression of CXCL6 in U2OS cells was confirmed by increased mRNA and protein levels of CXCL6. The volume and weight of xenograft tumors in CXCL6-overexpressed group were strikingly increased compared with those in NC group, which could be effectively restrained by treatment with SB225002, a potent and selective CXCR2 antagonist (Figures 7C-E). Moreover, the basal effect of SB225002 on the proliferation of OS cells was tested in vitro. As shown in Supplementary Figure 4, incubation with SB225002 


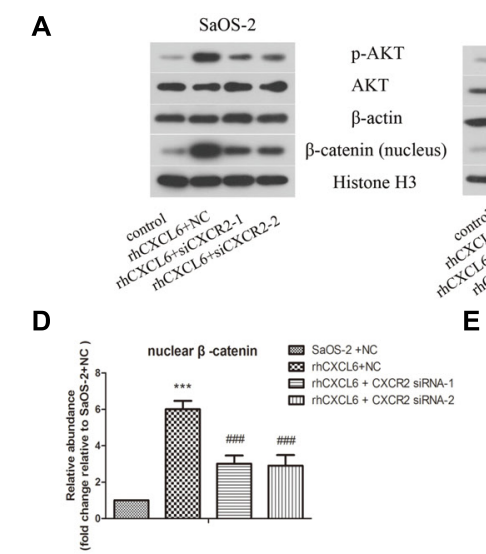

U2OS

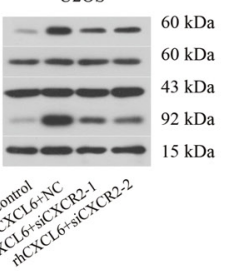

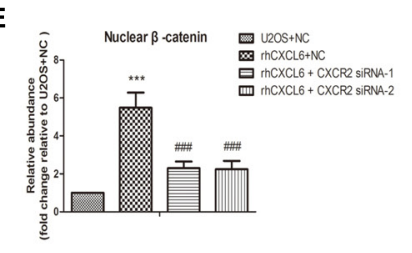
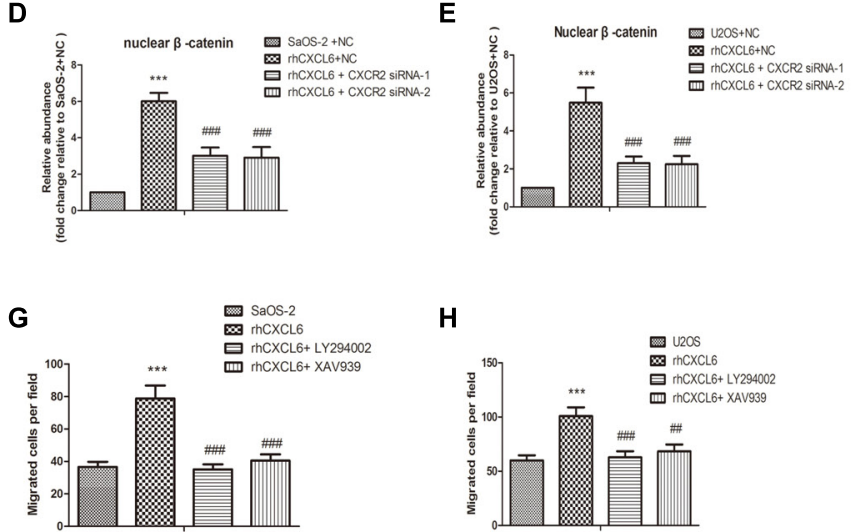

H

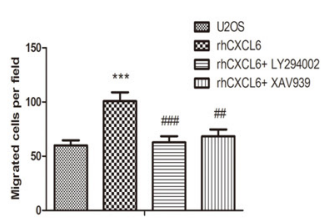

B C

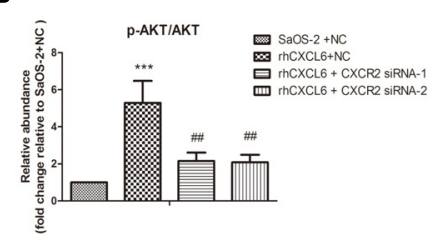

C

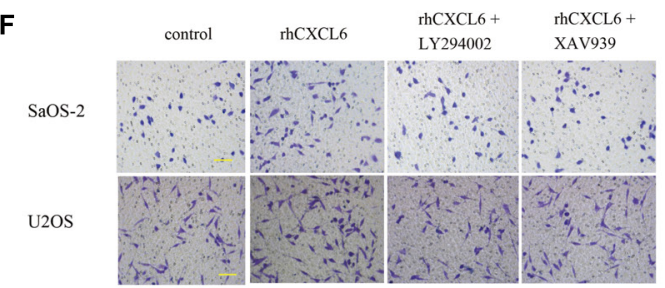

I

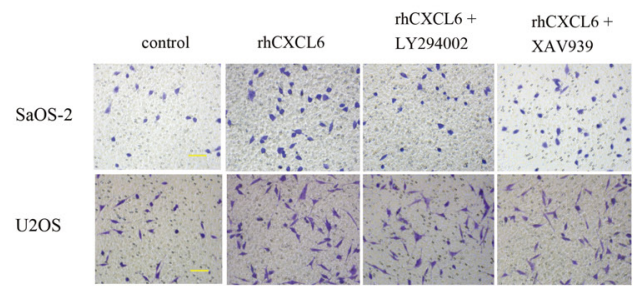

XCL $6+$
$J$

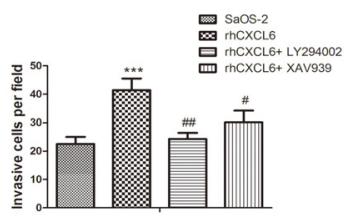

K

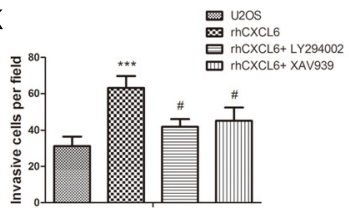

$\mathbf{L}$
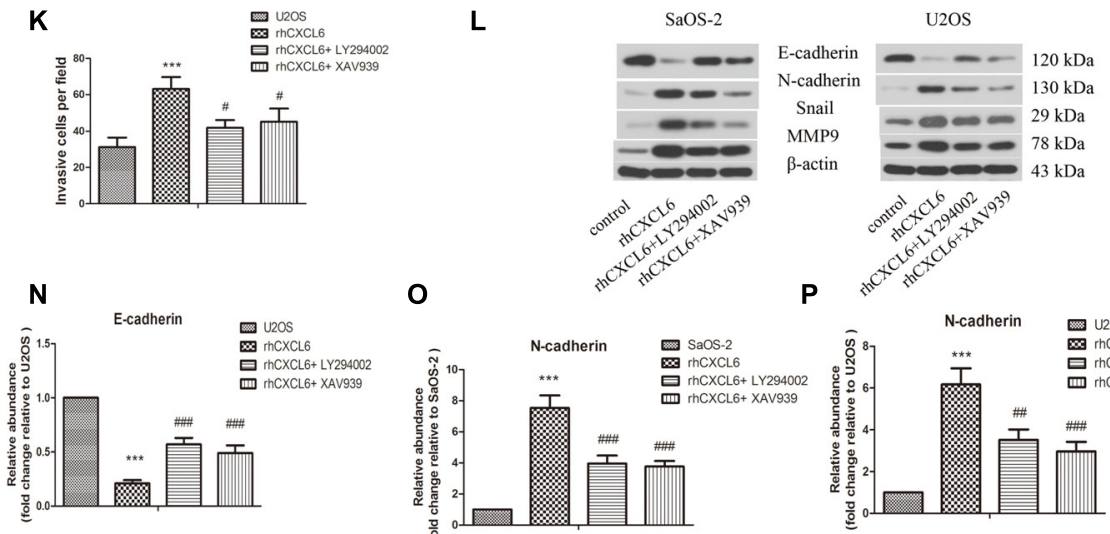

R

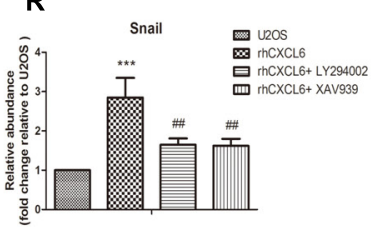

V
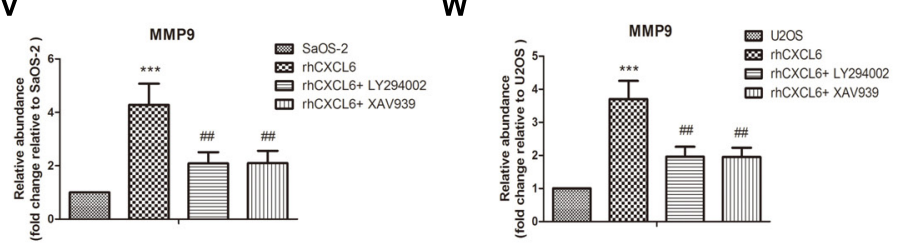

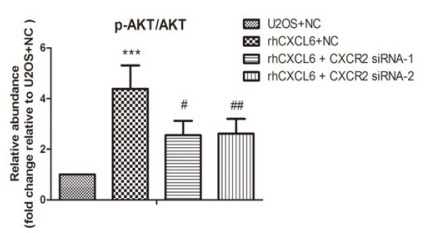

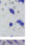
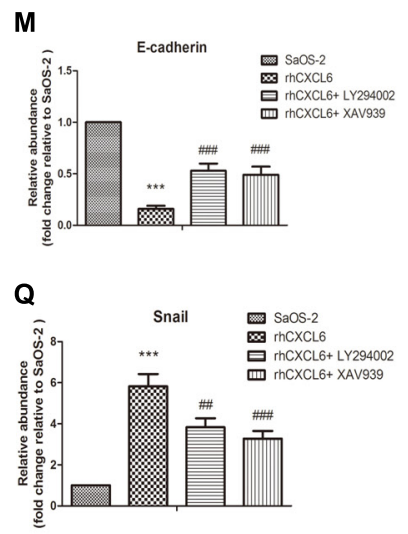

$\mathbf{U}$

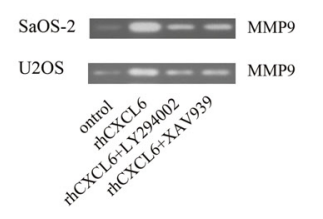

0

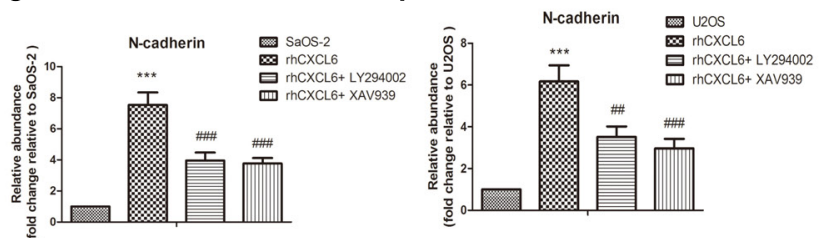

$\mathbf{S}^{2}$

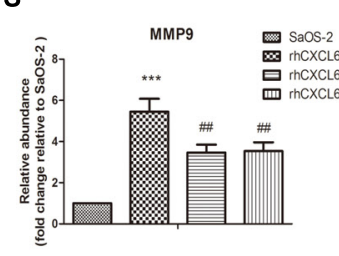

w
T

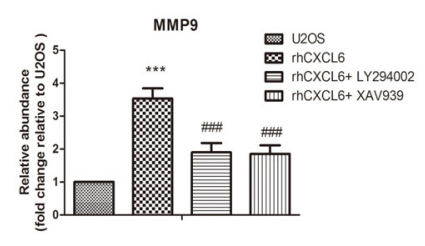

FIGURE 6 | PI3K/AKT and $\beta$-catenin signaling pathways participated in the regulation of migration, invasion and EMT by CXCL6/CXCR2 axis in OS cells. After transfection with siRNAs for $24 \mathrm{~h}$, OS cells were treated with $100 \mathrm{ng} / \mathrm{ml}$ rhCXCL6 for $24 \mathrm{~h}$. (A) The protein levels of p-AKT, AKT, and nuclear $\beta$-catenin in SaOS-2 and U2OS cells were detected by western blot assay. $\beta$-actin and Histone H3 were used as loading controls. (B-E) The protein quantification histograms were shown. OS cells were pre-treated with $50 \mu \mathrm{M}$ LY294002 or $10 \mu \mathrm{M}$ XAV939 for $1 \mathrm{~h}$, then treated with $100 \mathrm{ng} / \mathrm{ml}$ rhCXCL6 for $24 \mathrm{~h}$. (F) The migration of SaOS-2 and U2OS cells was detected by Transwell assay (no matrigel). Scal bar = $100 \mu \mathrm{m}$. (G,H) The number of migrated cells was shown. (I) The invasion of SaOS-2 and 


\section{FIGURE 6 | Continued}

U2OS cells was determined by Transwell assay (matrigel). Scal bar $=100 \mu \mathrm{m}$. (J,K) The number of invasive cells was shown. (L) The protein levels of E-cadherin, $\mathrm{N}$-cadherin, Snail, and MMP9 in SaOS-2 and U2OS cells were detected by western blot assay. (M-T) The protein quantification histograms were shown. (U) MMP-9 activity in the supernatant fluid of cultured SaOS-2 and U2OS cells was assessed by gelatin zymography assay. (V,W) The quantification histograms were shown.

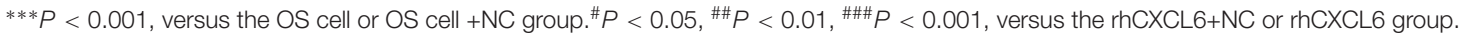

significantly suppressed the proliferation of MG63, 143B, SaOS2 , and U2OS cells. As illustrated in Figures 7F,G there were more PCNA-positive cells in tumors formed by CXCL6overexpressed cells, however, SB225002 treatment significantly suppressed PCNA expression. Moreover, the $\mathrm{p}-\mathrm{AKT} / \mathrm{AKT}$ ratio and nuclear $\beta$-catenin level in tumor tissues were enhanced in CXCL6-overexpressed group, whereas administration of SB225002 could reverse these changes (Figures 7H-J). As shown in Figures $\mathbf{7 K}, \mathbf{L}$ the number of lung metastatic nodes, as assessed by tail vein injection of U2OS cells, was promoted in CXCL6-overexpressed group, which was evidently suppressed by SB225002 treatment.

\section{DISCUSSION}

Chemokines are a kind of secreted proteins that take part in multiple physiological and pathological processes, including immunity, body's homeostatic regulation, oncogenesis, and so on (Baggiolini, 2001; Rot and Von Andrian, 2004). The proangiogenic ELR+CXCL family includes CXCL1, 2, 3, 5, 6, 7, and 8. A large body of research has suggested that these ELR+CXCLs promote the progression of cancer (Guo et al., 2017; Wang et al., 2017; Zhao et al., 2017; Xin et al., 2018). CXCL6 can be secreted from a variety of tumor cells, including OS cells, and plays crucial roles in the development of tumors (Gijsbers et al., 2005; Engl et al., 2006; Zhu et al., 2006). Like other ELR+CXCLs, CXCL6 was confirmed to have angiogenic properties in tumors (Van Coillie et al., 2001). It has been found that the plasma level of CXCL6 was up-regulated in OS patients, which associated with a poorer outcome (Li et al., 2011). However, the potential mechanisms of CXCL6 in the growth and metastasis of OS cells have not been determined. As OS cells secrete CXCL6 and express CXCR1 and CXCR2, we further evaluated the biological functions of CXCL6/CXCR1/2 axis in OS. Consistent with previous study, treatment with exogenous CXCL6 significantly promoted the proliferation of OS cells.

Next, we further investigated the effect of CXCL6 on metastasis of OS cells. Ma et al. reported that promoting CXCL6 secretion enhanced the metastatic potential of colon cancer ( $\mathrm{Ma}$ et al., 2017). Previous study also demonstrated that inhibition of CXCL6 expression restrained the migration and invasion of hepatocellular carcinoma cells (Tian et al., 2014). These studies indicated that CXCL6 was involved in the metastasis of tumor cells. According to our results, blocking the function of endogenous CXCL6 obviously inhibited the migration and invasion of OS cells, while adding exogenous rhCXCL6 had the opposite effect. So, these results suggested that CXCL6 participated in the metastasis of OS cells.
In the process of EMT, the expression of epithelial cell marker E-cadherin is reduced, while the expression of mesenchymal marker N-cadherin is increased (Yang et al., 2016). Snail is confirmed to be a regulator of EMT, which can suppress E-cadherin expression in transcription level (Nieto, 2002). In addition, increased activity of MMP9 may result in decrease in E-cadherin level, impaired cell adhesion and enhanced cell motility via inducing EMT (Cowden Dahl et al., 2008). Cheng et al. suggested that CXCL8 promoted the progression of colorectal cancer by inducing EMT (Cheng et al., 2014). Inhibition of CXCL2 by short hairpin RNA suppressed the expressions of EMT markers in colorectal cancer cells (Chen M.C. et al., 2018). Like CXCL2 or CXCL8, we suspected that CXCL6 might also regulate EMT process in OS cells. In the present study, treatment with anti-CXCL6 antibody significantly increased E-cadherin level, while reduced $\mathrm{N}$-cadherin and Snail levels. Moreover, rhCXCL6 administration had the opposite effect as we expected. These findings suggested that CXCL6 contributed to metastasis of OS cells via induction of EMT.

The ELR+CXC chemokines perform their biological functions through binding to CXCR1/2 receptors. Among them, only CXCL6, CXCL7 and CXCL8 bind to both CXCR1 and CXCR2, while the others bind to CXCR2 (Liu et al., 2016). Previous studies have demonstrated that CXCL8 and CXCL7 regulated the progression of various cancers via binding to CXCR1 and CXCR2 (Grepin et al., 2014; Liu et al., 2016). So, we further investigated whether CXCL6 regulated metastasis of OS cells via CXCR1/2. Inhibition of CXCR1/2 by SCH-527123 restrained cell proliferation, migration and invasion in melanoma (Shang and Li, 2018). The activation of CXCR1/Akt signaling pathway facilitated anoikis resistance and pulmonary metastasis of OS cells (Du et al., 2018). In addition, growing evidence has demonstrated that CXCR2 plays pivotal roles in the progression of various cancers (Ding et al., 2016; Maeda et al., 2017; Xiang et al., 2017). CXCR2 has been recognized as a predictor for the prognosis of gastric cancer patients, and also as a promising therapeutic target (Wang et al., 2015). However, it is not yet clear whether CXCR1/2 is involved in the malignant development of OS. According to our results, knockdown of CXCR2 strikingly repressed migration, invasion and EMT of OS cells with or without treatment with exogenous CXCL6. Therefore, CXCL6/CXCR1/2 axis participated in the metastasis of OS cells.

It has been well documented that $\mathrm{Wnt} / \beta$-catenin and $\mathrm{PI} 3 \mathrm{~K} / \mathrm{AKT}$ signaling pathways are aberrantly activated in multiple cancers, including OS (Park et al., 2015; Cui et al., 2018; Zhao et al., 2018). A large body of research indicated $\mathrm{PI} 3 \mathrm{~K} / \mathrm{AKT}$ pathway participated in most malignant phenotypes 
A

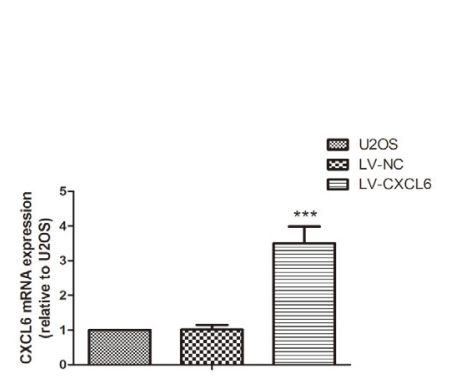

D

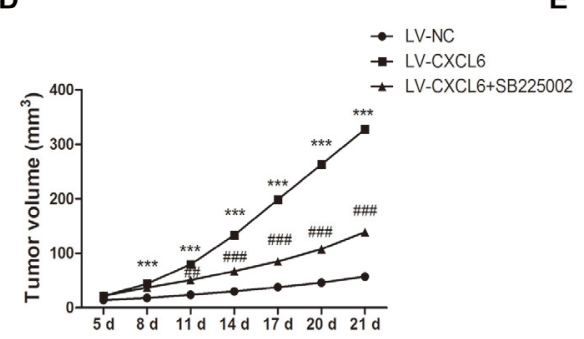

G

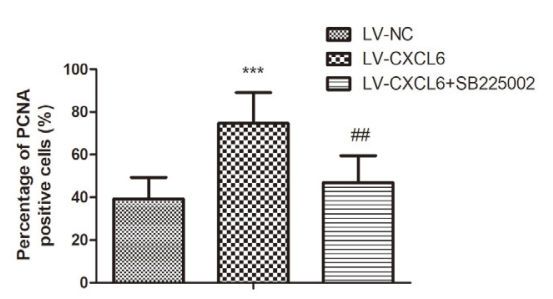

J

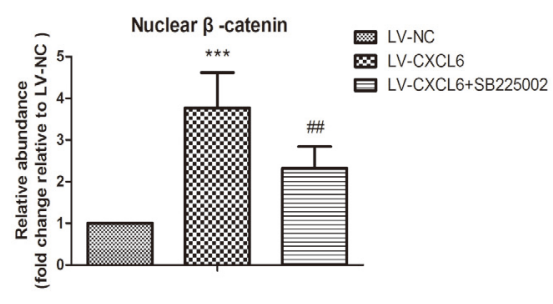

B
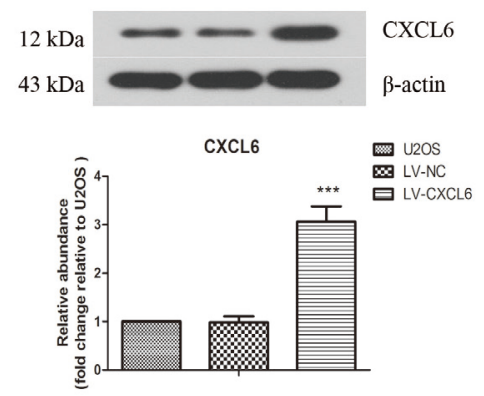

E

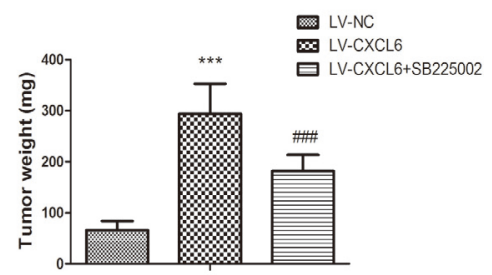

H

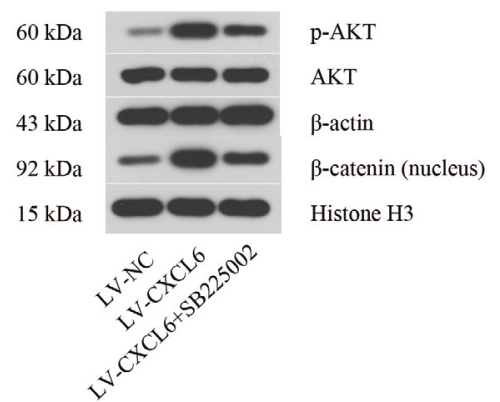

K LV-NC LV-CXCL6 $\quad$ SB225002

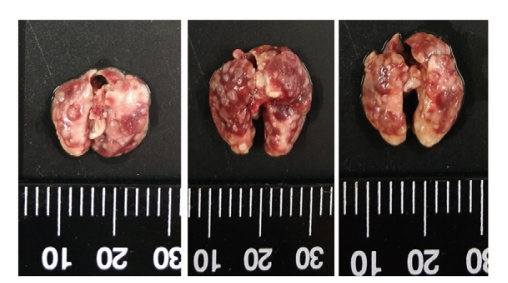

C

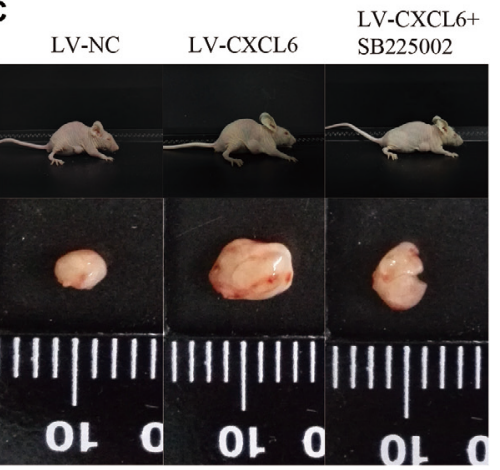

$\mathbf{F}$

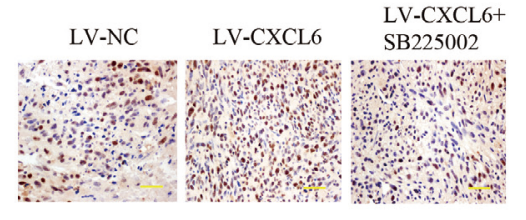

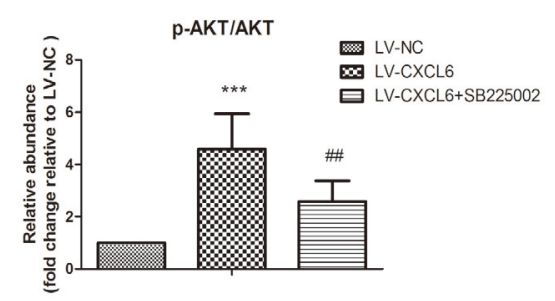

$\mathbf{L}$

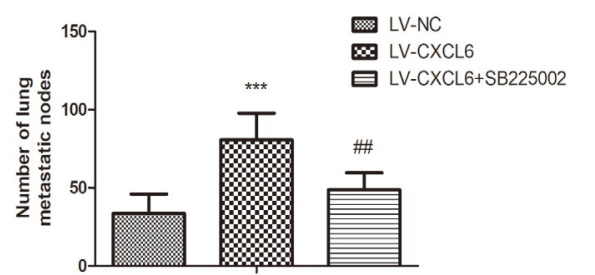

FIGURE 7 | Effect of CXCL6/CXCR2 axis on OS tumor growth and pulmonary metastasis in vivo. U2OS cells were infected with lentivirus expressing CXCL6 or NC. The mRNA (A) and protein level (B) of CXCL6 in U2OS cells were determined by real-time PCR and western blot assay. (C) After the injection of LV-CXCL6 or LV-NC U2OS cells for 21 days, the representative images of nude mice and their removed xenograft tumors were shown. (D) The tumor volume was calculated and the tumor growth-curve was shown. (E) The weight of xenograft tumors was shown. (F) The expression of PCNA in tumor tissues was detected by

immunohistochemical staining. Scal bar $=50 \mu \mathrm{m}$. (G) The percentage of PCNA positive cells were calculated and shown. (H) The protein levels of $\mathrm{p}-\mathrm{AKT}$, AKT, and nuclear $\beta$-catenin in tumor tissues were detected by western blot assay. $\beta$-actin and Histone $\mathrm{H} 3$ were used as loading controls. (I,J) The protein quantification histograms were shown. (K) Representative images of the lung of nude mice. (L) The number of lung metastatic nodes was quantified. ${ }^{* * *} P<0.001$, versus the LV-NC group. \#\# $P$ 0.01, \#\# $P<0.001$, versus the LV-CXCL6 group.

of OS, and accelerated the progression of OS (Chen J. et al., 2018; Jin et al., 2018). Furthermore, PI3K/AKT pathway may restrain GSK3 $\beta$ activation that promotes $\beta$-catenin degradation, so $\mathrm{PI} 3 \mathrm{~K} / \mathrm{AKT}$ facilitates $\mathrm{Wnt} / \beta$-catenin pathway activation
(Wu et al., 2012; Liu et al., 2013). In this study, our results showed that rhCXCL6 treatment promoted the activation of PI3K/AKT and Wnt/ $\beta$-catenin pathways, which could be inhibited by silencing of CXCR2. In addition, inactivation of 
$\mathrm{PI} 3 \mathrm{~K} / \mathrm{AKT}$ or $\mathrm{Wnt} / \beta$-catenin pathway significantly restrained rhCXCL6-induced migration, invasion, and EMT of OS cells. So $\mathrm{PI} 3 \mathrm{~K} / \mathrm{AKT}$ and $\mathrm{Wnt} / \beta$-catenin pathways were involved in the regulatory mechanisms of CXCL6/CXCR2 axis in OS metastasis.

Finally, the above findings were further verified in nude mice in vivo. The results suggested that overexpression of CXCL6 contributed to tumor growth and pulmonary metastasis via activating $\mathrm{PI} 3 \mathrm{~K} / \mathrm{AKT}$ and $\mathrm{Wnt} / \beta$-catenin pathways, which could be repressed by treatment with CXCR2 antagonist SB225002. Recently, increasing evidence indicated that the composition of tumor microenvironment contributes to the progression of cancer. The tumor microenvironment is composed of extracellular matrix and stromal cells, including fibroblasts, vessel cells, and inflammatory leukocytes (Raman et al., 2007). The chemokines secreted by tumor cells may regulate these cells (Raman et al., 2007). CXC chemokines and their receptors have been discovered to be involved in tumor-stromal interactions in tumor microenvironment (Sano et al., 2019). So, in this study, SB225002, as a CXCR2 antagonist, may also block the effect of CXCL6, CXCL8 on the communication between OS cells and tumor microenvironment, which needs to be evaluated in our future research.

\section{CONCLUSION}

Taken together, the present study demonstrated that CXCL6/CXCR1/2 axis promoted the proliferation, migration, invasion, and EMT of OS cells via activating PI3K/AKT and $\mathrm{Wnt} / \beta$-catenin pathways in vitro and in vivo.

\section{REFERENCES}

Baggiolini, M. (2001). Chemokines in pathology and medicine. J. Intern. Med. 250, 91-104. doi: 10.1046/j.1365-2796.2001.00867.x

Chen, J., Liu, C., Yang, Q. Q., Ma, R. B., Ke, Y., Dong, F., et al. (2018). Isoliquiritigenin suppresses osteosarcoma U2os cell proliferation and invasion by regulating the Pi3K/Akt signalling pathway. Chemotherapy 63, 155-161. doi: 10.1159/000490151

Chen, M. C., Baskaran, R., Lee, N. H., Hsu, H. H., Ho, T. J., Tu, C. C., et al. (2018). $\mathrm{Cxcl} 2 / \mathrm{Cxcr} 2$ axis induces cancer stem cell characteristics in Cpt-11-resistant lovo colon cancer cells via galphai-2 and galphaq/11. J. Cell Physiol. [Epub ahead of print].

Cheng, X. S., Li, Y. F., Tan, J., Sun, B., Xiao, Y. C., Fang, X. B., et al. (2014). Ccl20 and $\mathrm{Cxcl} 8$ synergize to promote progression and poor survival outcome in patients with colorectal cancer by collaborative induction of the epithelial-mesenchymal transition. Cancer Lett. 348, 77-87. doi: 10.1016/j.canlet.2014.03.008

Chou, A. J., and Gorlick, R. (2006). Chemotherapy resistance in osteosarcoma: current challenges and future directions. Expert Rev. Anticancer Ther. 6, 10751085. doi: 10.1586/14737140.6.7.1075

Cowden Dahl, K. D., Symowicz, J., Ning, Y., Gutierrez, E., Fishman, D. A., Adley, B. P., et al. (2008). Matrix metalloproteinase 9 is a mediator of epidermal growth factor-dependent E-cadherin loss in ovarian carcinoma cells. Cancer Res. 68, 4606-4613. doi: 10.1158/0008-5472.CAN-07-5046

Cui, H., Song, R., Wu, J., Wang, W., Chen, X., and Yin, J. (2018). Microrna337 regulates the Pi3K/Akt and wnt/beta-catenin signaling pathways to inhibit hepatocellular carcinoma progression by targeting high-mobility group at-hook 2. Am. J. Cancer Res. 8, 405-421.

Ding, D., Zhang, Y., Yang, R., Wang, X., Ji, G., Huo, L., et al. (2016). Mir940 suppresses tumor cell invasion and migration via regulation of $\mathrm{Cxcr} 2$ in

\section{DATA AVAILABILITY}

No datasets were generated or analyzed for this study.

\section{AUTHOR CONTRIBUTIONS}

PD and YS studied the concepts and design. GL, LA, and HZ performed experimental studies. GL, LA, and HZ contributed reagents, materials, and analysis tools. GL wrote the manuscript. PD and YS reviewed and edited the manuscript. YS acquired the funds and administered the project.

\section{FUNDING}

This study was supported by grants from the Science and Technology Development Planning Project of Jilin Province (Grant Nos. 20170311039YY and 20180520051JH), 13th 5-Year Science and Technology Project of Jilin Provincial Department of Education (Grant No. JJKH20170066KJ), and the Traditional Chinese Medicine Science and Technology Project of Jilin Province (Grant No. 2017084).

\section{SUPPLEMENTARY MATERIAL}

The Supplementary Material for this article can be found online at: https://www.frontiersin.org/articles/10.3389/fphar. 2019.00307/full\#supplementary-material

hepatocellular carcinoma. Biomed. Res. Int. 2016:7618342. doi: 10.1155/2016/ 7618342

Du, L., Han, X. G., Tu, B., Wang, M. Q., Qiao, H., Zhang, S. H., et al. (2018). Cxcr1/Akt signaling activation induced by mesenchymal stem cell-derived Il-8 promotes osteosarcoma cell anoikis resistance and pulmonary metastasis. Cell Death Dis. 9:714. doi: 10.1038/s41419-018-0745-0

Engl, T., Relja, B., Blumenberg, C., Muller, I., Ringel, E. M., Beecken, W. D., et al. (2006). Prostate tumor Cxc-chemokine profile correlates with cell adhesion to endothelium and extracellular matrix. Life Sci. 78, 1784-1793. doi: 10.1016/j.lfs. 2005.08.019

Gijsbers, K., Gouwy, M., Struyf, S., Wuyts, A., Proost, P., Opdenakker, G., et al. (2005). Gcp-2/Cxcl6 synergizes with other endothelial cell-derived chemokines in neutrophil mobilization and is associated with angiogenesis in gastrointestinal tumors. Exp. Cell Res. 303, 331-342. doi: 10.1016/j.yexcr.2004. 09.027

Grepin, R., Guyot, M., Giuliano, S., Boncompagni, M., Ambrosetti, D., Chamorey, E., et al. (2014). The $\mathrm{Cxcl} 7 / \mathrm{Cxcr1} / 2$ axis is a key driver in the growth of clear cell renal cell carcinoma. Cancer Res. 74, 873-883. doi: 10.1158/00085472.CAN-13-1267

Guo, Q., Jian, Z., Jia, B., and Chang, L. (2017). Cxcl7 promotes proliferation and invasion of cholangiocarcinoma cells. Oncol. Rep. 37, 1114-1122. doi: 10.3892/ or.2016.5312

Jin, C., Feng, Y., Ni, Y., and Shan, Z. (2017). Microrna-610 suppresses osteosarcoma oncogenicity via targeting twist1 expression. Oncotarget 8, 56174-56184. doi: 10.18632/oncotarget.17045

Jin, R., Jin, Y. Y., Tang, Y. L., Yang, H. J., Zhou, X. Q., and Lei, Z. (2018). Gpnmb silencing suppresses the proliferation and metastasis of osteosarcoma cells by blocking the Pi3K/Akt/mtor signaling pathway. Oncol. Rep. 39, 3034-3040. doi: 10.3892/Or.2018.6346 
Li, J., Tang, Z., Wang, H., Wu, W., Zhou, F., Ke, H., et al. (2018). Cxcl6 promotes non-small cell lung cancer cell survival and metastasis via down-regulation of mir-515-5P. Biomed. Pharmacother. 97, 1182-1188. doi: 10.1016/j.biopha.2017. 11.004

Li, Y., Flores, R., Yu, A., Okcu, M. F., Murray, J., Chintagumpala, M., et al. (2011). Elevated expression of Cxc chemokines in pediatric osteosarcoma patients. Cancer 117, 207-217. doi: 10.1002/cncr.25563

Liu, J., Zhang, Y., Xu, R., Du, J., Hu, Z., Yang, L., et al. (2013). Pi3K/Akt-dependent phosphorylation of gsk3beta and activation of rhoa regulate wnt5A-induced gastric cancer cell migration. Cell Signal. 25, 447-456. doi: 10.1016/j.cellsig. 2012.10.012

Liu, Q., Li, A., Tian, Y., Wu, J. D., Liu, Y., Li, T., et al. (2016). The Cxcl8-Cxcr1/2 pathways in cancer. Cytokine Growth Factor Rev. 31, 61-71. doi: 10.1016/j. cytogfr.2016.08.002

Ma, J. C., Sun, X. W., Su, H., Chen, Q., Guo, T. K., Li, Y., et al. (2017). Fibroblastderived Cxcl12/Sdf-1alpha promotes Cxcl6 secretion and co-operatively enhances metastatic potential through the Pi3K/Akt/Mtor pathway in colon cancer. World J. Gastroenterol. 23, 5167-5178. doi: 10.3748/wjg.v23.i28.5167

Maeda, S., Kuboki, S., Nojima, H., Shimizu, H., Yoshitomi, H., Furukawa, K., et al. (2017). Duffy antigen receptor for chemokines (Darc) expressing in cancer cells inhibits tumor progression by suppressing Cxcr2 signaling in human pancreatic ductal adenocarcinoma. Cytokine 95, 12-21. doi: 10.1016/j.cyto.2017. 02.007

Nieto, M. A. (2002). The snail superfamily of zinc-finger transcription factors. Nat. Rev. Mol. Cell. Biol. 3, 155-166. doi: 10.1038/nrm757

Ottaviani, G., and Jaffe, N. (2009). The epidemiology of osteosarcoma. Cancer Treat. Res. 152:3-13. doi: 10.1007/978-1-4419-0284-9_1

Park, G. B., Kim, D. J., Kim, Y. S., Lee, H. K., Kim, C. W., and Hur, D. Y. (2015). Silencing of Galectin-3 represses osteosarcoma cell migration and invasion through inhibition Of Fak/Src/Lyn activation and beta-catenin expression and increases susceptibility to chemotherapeutic agents. Int. J. Oncol. 46, 185-194. doi: 10.3892/Ijo.2014.2721

Proost, P., De Wolf-Peeters, C., Conings, R., Opdenakker, G., Billiau, A., and Van Damme, J. (1993). Identification of a novel granulocyte chemotactic protein (Gcp-2) from human tumor cells. in vitro and in vivo comparison with natural forms of GRO, IP-10, and IL-8. J. Immunol. 150, 1000-1010.

Raman, D., Baugher, P. J., Thu, Y. M., and Richmond, A. (2007). Role of chemokines in tumor growth. Cancer Lett. 256, 137-165. doi: 10.1016/j.canlet. 2007.05.013

Rot, A., and Von Andrian, U. H. (2004). Chemokines in innate and adaptive host defense: basic chemokinese grammar for immune cells. Annu. Rev. Immunol. 22, 891-928. doi: 10.1146/annurev.immunol.22.012703.104543

Sano, M., Ijichi, H., Takahashi, R., Miyabayashi, K., Fujiwara, H., Yamada, T., et al. (2019). Blocking Cxcls-Cxcr2 axis in tumor-stromal interactions contributes to survival in a mouse model of pancreatic ductal adenocarcinoma through reduced cell invasion/migration and a shift of immune-inflammatory microenvironment. Oncogenesis 8:8. doi: 10.1038/s41389-018-0117-8

Shang, F. M., and Li, J. (2018). A small-molecule antagonist of Cxcr1 And Cxcr2 inhibits cell proliferation, migration and invasion in melanoma via Pi3K/Akt pathway. Med. Clin. doi: 10.1016/j.medcli.2018.08.006 [Epub ahead of print].

Sobolik, T., Su, Y. J., Wells, S., Ayers, G. D., Cook, R. S., and Richmond, A. (2014). Cxcr4 drives the metastatic phenotype in breast cancer through induction of Cxcr2 and activation of Mek and Pi3K pathways. Mol. Biol. Cell 25, 566-582. doi: 10.1091/mbc.E13-07-0360

Tan, M. L., Choong, P. F., and Dass, C. R. (2009). Osteosarcoma: conventional treatment vs. gene therapy. Cancer Biol. Ther. 8, 106-117. doi: 10.4161/cbt.8. 2.7385

Tian, H., Huang, P., Zhao, Z., Tang, W., and Xia, J. (2014). Hif-1alpha plays a role in the chemotactic migration of hepatocarcinoma cells through the modulation of Cxcl6 expression. Cell Physiol. Biochem. 34, 1536-1546. doi: 10.1159/000366357

Van Coillie, E., Van Aelst, I., Wuyts, A., Vercauteren, R., Devos, R., De Wolf-Peeters, C., et al. (2001). Tumor angiogenesis induced by granulocyte chemotactic protein-2 as a countercurrent principle. Am. J. Pathol. 159, 1405-1414. doi: 10.1016/S0002-9440(10)62527-8
Verbeke, H., Struyf, S., Berghmans, N., Van Coillie, E., Opdenakker, G., Uyttenhove, C., et al. (2011). Isotypic neutralizing antibodies against mouse Gcp-2/Cxcl6 inhibit melanoma growth and metastasis. Cancer Lett. 302, 54-62. doi: 10.1016/j.canlet.2010.12.013

Wang, N., Zheng, Y., Gu, J., Cai, Y., Wang, S., Zhang, F., et al. (2017). Network-pharmacology-based validation of tams/Cxcl-1 as key mediator of xiaopi formula preventing breast cancer development and metastasis. Sci. Rep. 7:14513. doi: 10.1038/s41598-017-15030-3

Wang, Z., Liu, H., Shen, Z., Wang, X., Zhang, H., Qin, J., et al. (2015). The prognostic value of Cxc-chemokine receptor 2 (Cxcr2) in gastric cancer patients. BMC Cancer 15:766. doi: 10.1186/s12885-015-1793-9

Wolf, M., Delgado, M. B., Jones, S. A., Dewald, B., Clark-Lewis, I., and Baggiolini, M. (1998). Granulocyte chemotactic protein 2 acts via both Il-8 receptors, Cxcr1 and Cxcr2. Eur. J. Immunol. 28, 164-170. doi: 10.1002/(SICI) 1521-4141(199801)28:01<164::AID-IMMU164>3.0.CO;2-S

Wu, K., Fan, J., Zhang, L., Ning, Z., Zeng, J., Zhou, J., et al. (2012). Pi3K/Akt To Gsk3beta/beta-catenin signaling cascade coordinates cell colonization for bladder cancer bone metastasis through regulating ZEB1 transcription. Cell Signal. 24, 2273-2282. doi: 10.1016/j.cellsig.2012.08.004

Wu, P. K., Chen, W. M., Chen, C. F., Lee, O. K., Haung, C. K., and Chen, T. H. (2009). Primary osteogenic sarcoma with pulmonary metastasis: clinical results and prognostic factors in 91 patients. Jpn. J. Clin. Oncol. 39, 514-522. doi: 10.1093/jjco/hyp057

Xiang, Z., Zhou, Z. J., Xia, G. K., Zhang, X. H., Wei, Z. W., Zhu, J. T., et al. (2017). A positive crosstalk between Cxcr4 and Cxcr2 promotes gastric cancer metastasis. Oncogene 36, 5122-5133. doi: 10.1038/onc.2017.108

Xin, H., Cao, Y., Shao, M. L., Zhang, W., Zhang, C. B., Wang, J. T., et al. (2018). Chemokine $\mathrm{Cxcl} 3$ mediates prostate cancer cells proliferation, migration and gene expression changes in an autocrine/paracrine fashion. Int. Urol. Nephrol. 50, 861-868. doi: 10.1007/s11255-018-1818-9

Yang, W. H., Su, Y. H., Hsu, W. H., Wang, C. C., Arbiser, J. L., and Yang, M. H. (2016). Imipramine blue halts head and neck cancer invasion through promoting F-box and leucine-rich repeat protein 14-mediated twist1 degradation. Oncogene 35, 2287-2298. doi: 10.1038/onc.2015.291

Zhang, D., Wang, S., Chen, J., Liu, H., Lu, J., Jiang, H., et al. (2017). Fibulin4 promotes osteosarcoma invasion and metastasis by inducing epithelial to mesenchymal transition via the Pi3K/Akt/Mtor pathway. Int. J. Oncol. 50, 1513-1530. doi: 10.3892/ijo.2017.3921

Zhao, J., Ou, B., Han, D., Wang, P., Zong, Y., Zhu, C., et al. (2017). Tumor-derived Cxcl5 promotes human colorectal cancer metastasis through activation of the Erk/Elk-1/Snail and Akt/Gsk3beta/beta-catenin pathways. Mol. Cancer 16:70. doi: 10.1186/s12943-017-0629-4

Zhao, M., Xu, P., Liu, Z., Zhen, Y., Chen, Y., Liu, Y., et al. (2018). Dual roles of mir-374A by modulated C-Jun respectively targets ccnd1-inducing Pi3K/Akt signal and pten-suppressing Wnt/Beta-catenin signaling in non-small-cell lung cancer. Cell Death Dis. 9:78. doi: 10.1038/s41419-017-0103-7

Zhou, S. L., Zhou, Z. J., Hu, Z. Q., Li, X., Huang, X. W., Wang, Z., et al. (2015). Cxcr2/Cxcl5 axis contributes to epithelial-mesenchymal transition of hcc cells through activating Pi3K/Akt/Gsk-3beta/Snail signaling. Cancer Lett. 358, 124-135. doi: 10.1016/j.canlet.2014.11.044

Zhu, Y. M., Bagstaff, S. M., and Woll, P. J. (2006). Production and upregulation of granulocyte chemotactic protein-2/Cxcl6 By Il-1beta and hypoxia in small cell lung cancer. Br. J. Cancer 94, 1936-1941. doi: 10.1038/sj.bjc.6603177

Conflict of Interest Statement: The authors declare that the research was conducted in the absence of any commercial or financial relationships that could be construed as a potential conflict of interest.

Copyright (C) 2019 Liu, An, Zhang, Du and Sheng. This is an open-access article distributed under the terms of the Creative Commons Attribution License (CC BY). The use, distribution or reproduction in other forums is permitted, provided the original author(s) and the copyright owner(s) are credited and that the original publication in this journal is cited, in accordance with accepted academic practice. No use, distribution or reproduction is permitted which does not comply with these terms. 